\title{
Review Article \\ Dendritic Cells in Cord Blood Transplantation: A Review
}

\author{
Marta Isabel Pereira ${ }^{1}$ and Artur Paiva ${ }^{2}$ \\ ${ }^{1}$ Clinical Hematology Department, Coimbra University Hospitals, Coimbra, Portugal \\ ${ }^{2}$ Histocompatibility Center of Coimbra, 3000-075 Coimbra, Portugal \\ Correspondence should be addressed to Artur Paiva, apaiva@histocentro.min-saude.pt \\ Received 16 January 2011; Accepted 29 March 2011 \\ Academic Editor: Tsunehiko Komatsu
}

Copyright ( 2011 M. I. Pereira and A. Paiva. This is an open access article distributed under the Creative Commons Attribution License, which permits unrestricted use, distribution, and reproduction in any medium, provided the original work is properly cited.

Dendritic cells (DCs) are a heterogeneous population of antigen-presenting cells derived from hematopoietic progenitors that bridge the transition between the innate and adaptive immune responses, while maintaining self-tolerance and Th1/Th2 homeostasis, by priming other cells in either an immunogenic or tolerogenic direction. Through their role in both innate and adaptive immunity, DCs play a major part in transplant engraftment and rejection and in graft-versus-host disease (GvHD). Preferentially tolerogenic or immunogenic DC subtypes offer targets for immunotherapy, to optimize transplant success rates and prolong disease-free and overall survival. Cord blood DCs are immature and preferentially tolerogenic, due to maternal-fetal tolerance, leading to better graft acceptance and immune reconstitution and explaining the lower incidence and severity of GvHD in CB transplantation, despite donor-host mismatching. Manipulation of DC maturation and cell loading with tumor-antigens can direct antitumor immunity and target minimal residual disease, as demonstrated for acute myeloid leukemia, optimizing the graft-versus-leukemia effect.

\section{Dendritic Cells}

Dendritic cells (DCs) are a heterogeneous population of potent lineage-negative HLA-DR ${ }^{+}$antigen-presenting cells (APCs), derived from $\mathrm{CD} 34^{+}$hematopoietic progenitors that are present in small numbers in solid tissues and peripheral blood, and that bridge the transition between the innate immune response and adaptive responses, through their activation of $\mathrm{CD}^{+}{ }^{+} \mathrm{T}$-cells, $\mathrm{CD} 8^{+} \mathrm{T}$-cells, and $\mathrm{B}$-cells, while maintaining self-tolerance.

Recent data suggest that DCs arise from multilymphoid progenitors, along with lymphoid cells, monocytes, and macrophages [1], contradicting the classic and widely accepted model of early lymphoid-myeloid lineage segregation between the two main DC subsets, which can be differentiated through the expression of the inactivated-C3b receptor 4 (complement transmembrane protein) integrin alpha X chain (ITGAX or CD11c). This model postulates that CD11c ${ }^{-}$CD $123^{\text {high }} \mathrm{CD}^{-} 3^{-} \mathrm{CD} 16^{-}$plasmacytoid dendritic cells $(\mathrm{pDc})$ derive from a lymphoid progenitor cell, whereas $\mathrm{CD}_{11 \mathrm{c}^{+}} \mathrm{CD} 123^{\mathrm{dim}} \mathrm{CD} 3^{+} \mathrm{CD} 16^{-}$myeloid dendritic cells $(\mathrm{mDc})$ originate in a myeloid precursor cell [2-4]; the $\mathrm{mDc}$ subset can be further divided into distinct subpopulations, according to the expression of blood dendritic cell antigens-

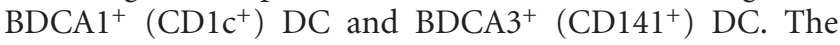
remaining BDCAs, $\mathrm{BDCA} 2$, and $\mathrm{BDCA} 4$ are expressed by $\mathrm{pDC}$ [4]. A third subtype of DC with a distinct immunophenotype has been described, comprising monocytoid-related $\mathrm{CD} 16^{+} \mathrm{CD} 14^{- \text {low }} \mathrm{CD} 123^{\text {inter }} \mathrm{CD} 33^{\text {inter }} \mathrm{DC}$, with a possible origin in differentiated mature monocytes which have downregulated or lost the monocyte marker CD14 [5-7].

Myeloid dendritic cells (also called DC 1) express tolllike receptor (TLR) 2 and TLR 4 and secrete IL-12, which alters the Th-cell balance in a Th1 direction, while pDc (also known as DC 2), physiologically residing in primary and secondary lymphoid organs, express TLR 7 and TLR 9 and secrete type I interferons (IFN) and prime a Th2 response. The latter subtype, through its ability to differentiate in vitro into mature classic DC, would provide the link between the innate response and the adaptive one [8]. The balance between Th1- and Th2-type immunity is thus dependent on the equilibrium between the different subsets of DC, the loss of which could lead to immune dysregulation, as suggested by observations of an epidemiological inverse relationship 
between infancy/childhood infections and an atopic potential, the basis of the so-called "hygiene hypothesis" [9], which is still controversial.

The pathogenic role of DC dysfunction (and its role as a potential therapeutic target) is the focus of continuing research, with descriptions of DC involvement in pathologic changes which have been associated with Th1/Th2 dysregulation, such as autoimmune disease (including rheumatic, neurologic and endocrine diseases [10-12], characterized by a Th1 response [13]) and allergy (including asthma, atopic dermatitis, and drug hypersensitivity [14-16], with a skew towards Th2 [13, 17]), and pDc being implicated in diseases with a Type I IfN-signature [18]. The rebalancing of Th1- and Th2-type responses, through Th2 stimulation in autoimmunity and Th1 shift in allergy, could be harnessed therapeutically $[9,19,20]$. Han et al. highlighted the role of DC in the re-regulation of the Th2 shift in allergy, by showing that DC isolated from Chlamydia muridaruminfected mice could inhibit allergen-induced systemic and local eosinophilia, on adoptive transfer [20].

The applications of immunotherapeutic DC vaccination, as a way of enhancing host anticancer immunity, is another developing field; the administration of DC loaded with leukemic cell antigens is a promising experimental treatment for minimal residual disease in acute myeloid leukemia and was the focus of a recent review by Van Den Ancker et al. [21].

Antigen presentation by DC can direct immune responses in both an immunogenic (stimulatory) and a tolerogenic direction [22], with various stages of maturation being associated with opposing functions. In a steady state, DC help to maintain self-tolerance, which is a central issue in immune homeostasis; in tissues, challenge by pathogens with stimulation of pattern-recognition receptors induces the maturation of immature sentinel resident DC, which then migrate towards the draining lymph nodes to present antigens to $\mathrm{T}$ cells and prime an adaptive specific response. However, the traditional view of a clear segregation between immature/tolerogenic and mature/immunogenic capabilities seems not to be a correct representation of DC function [23]; the induction of tolerance has been reported in immature, and partially mature DC phenotypes (similar to steady-state migratory veiled DC which tolerize lymph node T-cells towards self), whereas only the fully mature stage of DC differentiation would be immunogenic and able to release proinflammatory cytokines [24], with inflammatory stimuli converting a tolerogenic signal to a stimulatory one [22]. Current knowledge suggests that the induction of regulatory $\mathrm{T}$ cells $\left(\mathrm{T}_{\text {reg }}\right)$, and not just the lack of inflammatory signals, contributes to the maintenance of tolerance by immature DCs $[3,23]$.

Various authors have shown that DC maturity/immaturity can be manipulated, further optimizing the immunotherapeutic potential of these cell populations. DC maturation can be stimulated in vitro with increasing concentrations of growth hormone, resulting in increased IL-12 secretion and increased lymphocyte activation [25], with a Th1 shift, while the early addition of tumour-necrosis factor alpha (TNF- $\alpha$ ) to umbilical cord blood (cord blood, Св) mononuclear cell cultures enhances cell survival and increases DC maturation markers (CD80, CD83, CD86, and HLA-DR), also heightening IL-12 secretion by mature DC [26].

\section{Dendritic Cells in Transplantation}

One of the main complications of solid organ transplantation is the rejection of the engrafted tissue by the host's immune system, with loss of function. In allogeneic hematopoietic stem cell or bone marrow transplantation (allo-Вмт), the opposite can also happen, with the engrafted tissue rejecting the host's immune system, a phenomenon known as graft-versus-host disease (GvHD), which is responsible for a significant fraction of morbidity and both early [27] and late post-transplant death [28], due to organ damage and infection, in a context of immunodeficiency. A timeline has been used to separate acute GvHD (aGvHD), which takes place up to 100 days post-transplant and typically involves skin, the gastrointestinal tract, and the liver, from chronic (cGvHD) starting from the 100th day onward; cGvHD presents with a generalized systemic involvement and shares many of its features with autoimmune diseases, suggesting different pathogenic events from aGvHD [29]. The importance of DC and the Th1/Th2 homeostasis in autoimmunity has been described above.

The engrafted immune system, however, can also mount a response against the host's leukemic clone, a beneficial immunotherapeutic effect of allo-BмT described as the graftversus-leukemia $(\mathrm{GvL})$ effect, which can reduce primary disease relapse rates [30] but is diminished by the effort to combat GvHD, since part of the GvL effect is proportionally related to the intensity of GvHD [31, 32]. The benefit of the decrease in relapse rates due to GvL can be diluted by the increase in early and late death caused by GvHD, resulting in no effect on overall survival. As there also appears to be a direct antileukemic effect which is independent of GvHD [32], stem-cell transplantation should ideally evolve to exploit this effect while diminishing the impact of GvHD, to improve disease-free survival and overall survival.

Alloreactive $\mathrm{T}$ cells are responsible for the rejection of allografts through major histocompatibility complex (Mнс) cross-recognition. GvHD is due to donor (graft) T-cell recognition of $\mathrm{MHC}$ and minor histocompatibility antigen (miHAg) mismatches between graft and host, with aGvHD depending on donor $\mathrm{CD}^{+} \mathrm{T}$-cells and $\mathrm{cGvHD}$ originating with donor $\mathrm{CD}^{+}{ }^{+} \mathrm{T}$-cells $[33,34]$.

The in vitro and ex vivo manipulation of the stage of DC maturation, with a selection of the tolerogenic preferentially immature stage, has previously been shown to be able to induce allotolerance by specifically targeting alloreactive $\mathrm{T}$ cells, suggesting a role for the use of manipulated donor or recipient DC in the management of transplant engraftment and rejection [35]. Animal models of solid organ transplantation have shed light on the importance of DC in alloimmunity; in rats, the transplantation of a donor heart deprived of its DC population and repopulated with hostDC prior to transplantation, in an effort to favour tolerance, 
found, instead, an acute rejection of the organ, starting in situ in the donor [36], demonstrating that both host and donor immune cells play an important role in GvHD. Several published studies have further clarified the role of donor and host Apcs. In the murine model, it has been shown that, immediately after transplantation, and before clearance of host DC, the latter activate donor $\mathrm{CD}^{+} \mathrm{T}$ cells which, in turn, start the aGvHD response $[33,34,37]$. cGvHD, on the other hand, appears to be dependent on either host or graft ApCs $[33,34]$. In humans, the role of DC in transplantation is perhaps best exemplified by the rapid acute rejection of skin allografts, which has been attributed to the skin's richness in a resident skin-homing DC population (Langerhans' cells) [38], and which has limited the field of skin transplantation. The early finding that the immunosuppressive antiGvHD drug sirolimus (rapamycin) exerts its effect through DC modulation (including modulation of maturation [39], macropinocytosis and endocytosis [40], antigen uptake [41], and signaling and apoptosis [42-44]) further emphasized the role of Dc in the GvHD response. Klangsinsirikul et al. have supported the previous findings by showing that the elimination of the host Apcs diminishes the intensity of GvHD [45], while Sato and colleagues have shown that hostderived regulatory $\mathrm{DC}\left(\mathrm{Dc}_{\mathrm{reg}}\right)$ generated in vitro that express Mнс Class II and lack expression of immune costimulatory molecules were more effective in preventing GvHD than classic tolerogenic DC, through the induction of T-cell anergy due to diminished co-stimulation, despite the presence of a potent antigenic signal $[46,47]$. The same authors identified a naturally occurring population of $\mathrm{Dc}_{\mathrm{reg}}\left(\mathrm{CD} 49 \mathrm{~b}^{+}\right.$ $\mathrm{CD}_{200 \mathrm{R}^{+}}$) in a murine model of MHC-compatible, miHAgincompatible allo-BMT, which suppressed cutaneous cGvHD through a decrease in proinflammatory cytokines and a diminished donor $\mathrm{CD} 4^{+} \mathrm{T}$-cell alloreaction [48]. Their work in a murine model has also shown that $\mathrm{Dc}_{\mathrm{reg}}$ cells are associated with a decreased rate of post-transplant leukemic relapse, demonstrating the possibility of obtaining a strong GvL effect separate from the GvHD response [46] and further highlighting the importance of the manipulation of DC subpopulations as a way to increase disease-free survival in progenitor cell transplantation. In fact, recent studies $[49,50]$ have identified a population of $\mathrm{CD} 8 \alpha^{+} \mathrm{T}$ cell receptor $(\mathrm{TCR})^{-}$facilitating cells (FCs) that enhance allo-Bмт engraftment and tolerance, and decrease GvHD, and have characterized the main subpopulation of FC as plasmacytoid precursor dendritic cells (p-preDCs) which can induce antigen-specific $\mathrm{T}_{\text {reg }}$.

Tolerogenic DC, through their ability to induce $\mathrm{T}_{\text {reg }}$ expansion, have also been shown to confer protection from autoimmune diseases. Il-10, transforming growth factor beta $\left(\mathrm{TGF}_{\mathrm{G}} \beta\right)$, granulocyte colony-stimulating factor (G-CsF), hepatocyte growth factor (HGF), and vasoactive intestinal peptide (VIP) have all been found to modulate DC maturation, favoring the differentiation of tolerogenic DC, an ability which may be harnessed therapeutically for the treatment or prevention of autoimmunity, graft rejection and GvHD [23].

\section{Dendritic Cells in Cord Blood Transplantation}

Immunologically, umbilical Cв differs from adult peripheral blood, as a consequence of its function, simultaneously reflecting the need to prevent mother/fetus alloimmunization and the diminished immune stimulation due to the reduced antigenic load of the intrauterine environment.

Among the differences described are a diminished percentage of DC and specific CD14 ${ }^{+}$monocyte subsets [51]; nevertheless, Св is a rich source of hematopoietic stem cells and progenitor cells, and immune cells (including DC) at an immature stage of differentiation. In fact, the phenotype of fetal and neonatal/infant DC (as determined by flow cytometry) is skewed towards immaturity, when compared with adult DC, with a suggestion of decreased ability to take up antigens through IgG-mediated mechanisms (as revealed by a decreased expression of the IgG receptors CD32 and CD64) and reduced co-stimulation [52]. A decrease in co-stimulation was one of the characteristics identified by Sato et al., in $\mathrm{Dc}_{\text {reg }}$, in the studies described above [4648]. Furthermore, other authors have found that Св DCs secrete less TNF- $\alpha$ and IFn- $\alpha$, after stimulation, than Рв DCs [51]. Plasmacytoid and $\mathrm{mDC}$ responses to TLR 4 agonists (bacterial lipopolysaccharide) and TLR 9 agonists (CpG oligonucleotides) are decreased in the neonate and infant, when compared to adult responses and increase during the first year of life [53]. Other studies, however, have suggested that Св Dс have better antigen-presenting capabilities than peripheral blood or bone marrow DC, as represented by an increase in antigen-positive endosomes on fluorescent microscopy [54], findings which can also be viewed in light of Sato's description of potent antigen signaling without costimulation [46-48].

The overall status of the fetal/neonatal immune system seems to be skewed in a Th2 direction, with a decrease in adaptive responses, which is in part responsible for a heightened susceptibility to infections in infancy $[55,56]$ (and consequent dependence on the mother's immune system), but which is necessary to avoid Th1-dependent mother/fetus alloimmunization [57]; the mature Th1/Th2 balance is acquired by the naïve immune system through exposure to microbial antigens, a process which is necessary to avoid immune dysfunction such as allergy or autoimmunity [58], as previously described.

The diminished tendency for alloimmunization which is characteristic of $\mathrm{CB}$ could theoretically be harnessed for transplantation, with reduced alloreactivity between host and donor. Consequently, human $\mathrm{CB}_{\mathrm{B}}$ was used for the first time as the source of hematopoietic stem cells for transplantation just over two decades ago by Gluckman et al. [59] and, since that first description, Св transplantation has been observed to be associated with less frequent and less severe GvHD than allo-Вмт [60], allowing for a higher degree of mismatching between donor and host.

Several factors have been identified which contribute to the decreased incidence of GvHD with $\mathrm{CB}$, involving both adaptive and innate immunity, and including phenotypic or 
functional immaturity, reduced proinflammatory cytokineproducing T-cell populations and increased immunosuppressive factors [61-65]. That the diminished GvHD response could also in part be due to the differences in the DC populations found in the two tissues, is demonstrated by the different expression of the human leukocyte antigen (HLA)-G [66] and the lower expression of cell-surface markers involved in DC/T-cell interaction [67]. Св monocytes and $\mathrm{CB}_{\mathrm{B}} \mathrm{CD}_{16} 6^{+} \mathrm{CD} 14^{-/ \text {low }} \mathrm{DC}$ produce lower basal levels of cytokines (Il-1 $\beta$, Il- 6 , Il-12, and TNF- $\alpha$ ), when compared to peripheral blood, with identical responses to stimulation, reflecting the reduced antigen stimulation in utero, but suggesting that the ability to respond to stimulation shown by monocytes and $\mathrm{CD}_{1} 6^{+} \mathrm{CD} 14^{-/ \text {low }} \mathrm{DCs}$ reflects cellular maturity [5]. The analysis of the three DC subpopulations has pointed at lower absolute and relative numbers of $\mathrm{CD} 16^{+}$ $\mathrm{CD}_{123}{ }^{\text {inter }} \mathrm{CD} 3^{\text {inter }} \mathrm{DC}$ in Св [68], the subset that expresses the highest amounts of proinflammatory cytokines $[69,70]$, which would contribute to the relative immune immaturity of $\mathrm{CB}$ [68].

Several authors have found a decrease in the frequency of monocytes expressing Il-12 and TNF- $\alpha$ in $\mathrm{CB}_{\mathrm{B}}[5,51]$, which could help to explain the decreased Th1 response and alloimmunization described for fetal/neonate blood and, consequently, the reduced inflammation and diminished GvHD incidence and severity [5] that has been reported in $\mathrm{CB}_{B}$ transplantation. On the other hand, the factors listed above can also explain the increased incidence of infectious complications which has been described by some authors in transplantation [71], a parallel of neonate/infant infectious susceptibility. The complex relationship between infectious complications and GvHD was clinically demonstrated by initial unexpected descriptions of reduced cytomegalovirus (CMv) reactivation rates in patients undergoing sirolimus prophylaxis of GvHD after allo-Bмт, which led Marty et al. to publish a retrospective analysis that confirmed a protective effect against CMv [72], a result which could take into account both the role of CMv infection on DC function impairment [73], and the modulatory effects of sirolimus on DC function, described above.

Adding to the putative causes of the higher Св transplantation success, is the increase in CXCR4 in Св attributed to immune immaturity, and which could lead to improved engraftment [5] and decreased graft rejection, with a potential for improving disease-free survival. The described ability of Св DCs to efficiently induce $\mathrm{T}_{\text {reg }}$ expansion, despite other markers of immaturity, contributes to graft tolerance in Св allo-Bмт [51].

Immune reconstitution after transplantation has been compared for Св and allo-Вмт; Moretta et al. found that reconstitution was not only comparable between the two progenitor cell sources, but $\mathrm{C}_{\mathrm{B}}$ recipients actually showed a higher number of $\mathrm{B}$ cells, with a better $\mathrm{CD} 4^{+} \mathrm{T}$-cell recovery in unrelated $\mathrm{C}_{B}$ recipients, which the authors attributed to the decreased GvHD effect [71]. In human allo-Bмт, Arpinati et al. suggested that DC reconstitution was impaired by the presence of an aGvHD response, as well as by steroid treatment [74], which would point at a bidirectional influence, with DC regulating GvHD, and the latter impacting on DC reconstitution. This bidirectional effect of GvHD on the success of regaining a normal population of DC could also partly justify the very high incidence of infectious complications described in GvHD [75]. Thus, Св transplantation could help to reduce GvHD-related infectious complications, though the positive benefit might be offset by the infectious susceptibility described above.

Finally, Св GvL effect has also been favourably compared to peripheral blood, with recent studies showing that Св DC enhance the proliferative capability and antileukemia effect of Св cytokine-induced killer (CIк) cells, when compared to $\mathrm{C}_{\mathrm{B}}$ CIK cells alone, with a higher proliferative ability than peripheral blood DC-Cik cells [76].

In conclusion, DC populations, through their central role in both innate and adaptive immunity, play a major part in transplant acceptance, engraftment, and rejection, and in graft-versus-host disease, through either their tolerogenic or immunogenic functions, and the maintenance of the Th1/Th2 balance. The identification of population subtypes with a preference for tolerance or for immune stimulation will offer targets for immunotherapy and cellular manipulation, to optimize transplant success rates, decreasing early and late transplant-associated death, as well as primary disease relapse, prolonging disease-free survival and overall survival.

Cord blood DC are immature, as a consequence of necessary maternal-fetal tolerance and fetal immune naïveté, which renders them preferentially tolerogenic and, therefore, theoretically associated with better graft acceptance and immune reconstitution, while helping to explain the lower incidence and severity of GvHD in Св transplantation, even in the presence of donor-host mismatching.

The ex vivo or in vitro manipulation of DC, through the induction of maturation and cell loading with specific tumor antigens, can direct antitumor immunity and target minimal residual disease, as demonstrated for acute myeloid leukemia, optimizing the graft-versus-leukemia effect and dissociating it from the GvHD.

\section{References}

[1] S. Doulatov, F. Notta, K. Eppert, L. T. Nguyen, P. S. Ohashi, and J. E. Dick, "Revised map of the human progenitor hierarchy shows the origin of macrophages and dendritic cells in early lymphoid development," Nature Immunology, vol. 11, no. 7, pp. 585-593, 2010.

[2] J. Olweus, A. BitMansour, R. Warnke et al., "Dendritic cell ontogeny: a human dendritic cell lineage of myeloid origin," Proceedings of the National Academy of Sciences of the United States of America, vol. 94, no. 23, pp. 12551-12556, 1997.

[3] N. Cools, P. Ponsaerts, V. F. I. Van Tendeloo, and Z. N. Berneman, "Balancing between immunity and tolerance: an interplay between dendritic cells, regulatory $\mathrm{T}$ cells, and effector T cells," Journal of Leukocyte Biology, vol. 82, no. 6, pp. 1365-1374, 2007.

[4] A. Dzionek, A. Fuchs, P. Schmidt et al., "BDCA-2, BDCA-3, and BDCA-4: three markers for distinct subsets of dendritic cells in human peripheral blood," Journal of Immunology, vol. 165, no. 11, pp. 6037-6046, 2000. 
[5] J. M. Morgado, R. Pratas, P. Laranjeira et al., "The phenotypical and functional characteristics of cord blood monocytes and $\mathrm{CD} 14(-/ \mathrm{low}) / \mathrm{CD} 16(+)$ dendritic cells can be relevant to the development of cellular immune responses after transplantation," Transplant Immunology, vol. 19, no. 1, pp. 55-63, 2008.

[6] R. Thomas and P. E. Lipsky, "Human peripheral blood dendritic cell subsets: isolation and characterization of precursor and mature antigen-presenting cells," Journal of Immunology, vol. 153, no. 9, pp. 4016-4028, 1994.

[7] K. Schäkel, E. Mayer, C. Federle, M. Schmitz, G. Riethmüller, and E. P. Rieber, "A novel dendritic cell population in human blood: one-step immunomagnetic isolation by a specific $\mathrm{mAb}$ (M-DC8) and in vitro priming of cytotoxic T lymphocytes," European Journal of Immunology, vol. 28, no. 12, pp. 40844093, 1998.

[8] A. G. Jegalian, F. Facchetti, and E. S. Jaffe, "Plasmacytoid dendritic cells physiologic roles and pathologic states," Advances in Anatomic Pathology, vol. 16, no. 6, pp. 392-404, 2009.

[9] X. Yang and X. Gao, "Role of dendritic cells: a step forward for the hygiene hypothesis," Cellular and Molecular Immunology, vol. 8, no. 1, pp. 12-18, 2011.

[10] N. J. Zvaifler, R. M. Steinman, and G. Kaplan, "Identification of immunostimulatory dendritic cells in the synovial effusions of patients with rheumatoid arthritis," Journal of Clinical Investigation, vol. 76, no. 2, pp. 789-800, 1985.

[11] T. Suter, U. Malipiero, L. Otten et al., "Dendritic cells and differential usage of the MHC class II transactivator promoters in the central nervous system in experimental autoimmune encephalitis," European Journal of Immunology, vol. 30, no. 3, pp. 794-802, 2000.

[12] M.-H. Lee, W.-H. Lee, I. Todorov, and C.-P. Liu, "CD4+CD25+ regulatory $\mathrm{T}$ cells prevent type 1 diabetes preceded by dendritic cell-dominant invasive insulitis by affecting chemotaxis and local invasiveness of dendritic cells," Journal of Immunology, vol. 185, no. 4, pp. 2493-2501, 2010.

[13] A. Berger, "Th1 and Th2 responses: what are they?" British Medical Journal, vol. 321, no. 7258, p. 424, 2000.

[14] G. E. Kaiko and P. S. Foster, "New insights into the generation of Th2 immunity and potential therapeutic targets for the treatment of asthma," Current Opinion in Allergy and Clinical Immunology, vol. 11, no. 1, pp. 39-45, 2011.

[15] W. Yao, J. Chang, S. Sehra et al., "Altered cytokine production by dendritic cells from infants with atopic dermatitis," Clinical Immunology, vol. 137, no. 3, pp. 406-414, 2010.

[16] C. M. F. Lima, J. T. Schroeder, C. E. S. Galvão, F. M. Castro, J. Kalil, and N. F. Adkinson, "Functional changes of dendritic cells in hypersensitivity reactions to amoxicillin," Brazilian Journal of Medical and Biological Research, vol. 43, no. 10, pp. 964-968, 2010.

[17] S. Romagnani, "Immunologic influences on allergy and the T1/T2 balance," Journal of Allergy and Clinical Immunology, vol. 113, no. 3, pp. 395-400, 2004.

[18] S. Sozzani, W. Vermi, A. D. Prete, and F. Facchetti, “Trafficking properties of plasmacytoid dendritic cells in health and disease," Trends in Immunology, vol. 31, pp. 270-277, 2010.

[19] E. F. Rosloniec, K. Latham, and Y. B. Guedez, "Paradoxical roles of IFN- $\gamma$ in models in Th1-mediated autoimmunity," Arthritis Research, vol. 4, no. 6, pp. 333-336, 2002.

[20] X. Han, Y. Fan, S. Wang et al., "Dendritic cells from Chlamydia-infected mice show altered Toll-like receptor expression and play a crucial role in inhibition of allergic responses to ovalbumin," European Journal of Immunology, vol. 34, no. 4, pp. 981-989, 2004.
[21] W. Van Den Ancker, M. M. Van Luijn, T. M. Westers et al., "Recent advances in antigen-loaded dendritic cell-based strategies for treatment of minimal residual disease in acute myeloid leukemia," Immunotherapy, vol. 2, no. 1, pp. 69-83, 2010.

[22] F. D. Finkelman, A. Lees, R. Birnbaum, W. C. Gause, and S. C. Morris, "Dendritic cells can present antigen in vivo in a tolerogenic or immunogenic fashion," Journal of Immunology, vol. 157, no. 4, pp. 1406-1414, 1996.

[23] S. Rutella, S. Danese, and G. Leone, "Tolerogenic dendritic cells: cytokine modulation comes of age," Blood, vol. 108, no. 5, pp. 1435-1440, 2006.

[24] M. B. Lutz and G. Schuler, "Immature, semi-mature and fully mature dendritic cells: which signals induce tolerance or immunity?" Trends in Immunology, vol. 23, no. 9, pp. 445-449, 2002.

[25] Q. L. Liu, Y. S. Wang, and J. X. Wang, "Effect of growth hormone on the immune function of dendritic cells," Chinese Medical Journal, vol. 123, no. 8, pp. 1078-1083, 2010.

[26] M. Ebrahimi, Z. M. Hassan, J. Hadjati, P. Hayat, and S. M. Moazzeni, "Immediate exposure to TNF-alpha activate dendritic cells derived from non-purified cord blood mononuclear cells," Iranian Journal of Immunology, vol. 6, no. 3, pp. 107-118, 2009.

[27] A. Valls, M. Algara, J. Marrugat, E. Carreras, J. Sierra, and A. Granena, "Risk factors for early mortality in allogeneic bone marrow transplantation. A multivariate analysis on 174 leukaemia patients," European Journal of Cancer A, vol. 29, no. 11, pp. 1523-1528, 1993.

[28] G. Socié, J. V. Stone, J. R. Wingard et al., "Long-term survival and late deaths after allogeneic bone marrow transplantation," New England Journal of Medicine, vol. 341, no. 1, pp. 14-21, 1999.

[29] D. Gaziev, M. Galimberti, G. Lucarelli, and P. Polchi, "Chronic graft-versus-host disease: is there an alternative to the conventional treatment?" Bone Marrow Transplantation, vol. 25, no. 7, pp. 689-696, 2000.

[30] C. L. Toze, A. Galal, M. J. Barnett et al., "Myeloablative allografting for chronic lymphocytic leukemia: evidence for a potent graft-versus-leukemia effect associated with graftversus-host disease," Bone Marrow Transplantation, vol. 36, no. 9, pp. 825-830, 2005.

[31] P. Zhang, B. J. Chen, and N. J. Chao, "Prevention of GVHD without losing GVL effect: windows of opportunity," Immunologic Research, vol. 49, no. 1-3, pp. 49-55, 2011.

[32] M. M. Horowitz, R. P. Gale, P. M. Sondel et al., "Graft-versusleukemia reactions after bone marrow transplantation," Blood, vol. 75, no. 3, pp. 555-562, 1990.

[33] B. E. Anderson, J. M. McNiff, C. Matte, I. Athanasiadis, W. D. Shlomchik, and M. J. Shlomchik, "Recipient CD4+ T cells that survive irradiation regulate chronic graft-versus-host disease," Blood, vol. 104, no. 5, pp. 1565-1573, 2004.

[34] B. E. Anderson, J. M. McNiff, D. Jain, B. R. Blazar, W. D. Shlomchik, and M. J. Shlomchik, "Distinct roles for donor- and host-derived antigen-presenting cells and costimulatory molecules in murine chronic graft-versus-host disease: requirements depend on target organ," Blood, vol. 105, no. 5, pp. 2227-2234, 2005.

[35] M. Nouri-Shirazi and E. Guinet, "Direct and indirect crosstolerance of alloreactive $\mathrm{T}$ cells by dendritic cells retained in the immature stage," Transplantation, vol. 74, no. 7, pp. 10351044, 2002. 
[36] M. Maksymowicz, W. L. Olszewski, and E. Cybulska, "Repopulation of donor heart by recipient bone marrow-derived dendritic cells prior to transplantation causes acute rejection by both the allogeneic and syngeneic recipient," Transplantation Proceedings, vol. 35, no. 6, pp. 2374-2375, 2003.

[37] Y. Zhang, J. P. Louboutin, J. Zhu, A. J. Rivera, and S. G. Emerson, "Preterminal host dendritic cells in irradiated mice prime CD8+ T cell-mediated acute graft-versus-host disease," Journal of Clinical Investigation, vol. 109, no. 10, pp. 13351344, 2002.

[38] H. Galkowska, "Dendritic cells as regulators of immune reactivity: implications for skin transplantation," Annals of Transplantation, vol. 9, no. 2, pp. 5-10, 2004.

[39] H. Hackstein, T. Taner, A. F. Zahorchak et al., "Rapamycin inhibits IL-4-induced dendritic cell maturation in vitro and dendritic cell mobilization and function in vivo," Blood, vol. 101, no. 11, pp. 4457-4463, 2003.

[40] H. Hackstein, T. Taner, A. J. Logar, and A. W. Thomson, "Rapamycin inhibits macropinocytosis and mannose receptor-mediated endocytosis by bone marrow-derived dendritic cells," Blood, vol. 100, no. 3, pp. 1084-1087, 2002.

[41] P. Monti, A. Mercalli, B. Eugenio Leone, D. C. Valerio, P. Allavena, and L. Piemonti, "Rapamycin impairs antigen uptake of human dendritic cells," Transplantation, vol. 75, no. 1, pp. 137-145, 2003.

[42] P. H. Chiang, L. Wang, Y. Liang et al., "Inhibition of IL-12 signaling Stat $4 / \mathrm{IFN}-\gamma$ pathway by rapamycin is associated with impaired dendritc cell function," Transplantation Proceedings, vol. 34, no. 5, pp. 1394-1395, 2002.

[43] A. M. Woltman, J. W. De Fijter, S. W. A. Kamerling et al., "Rapamycin induces apoptosis in monocyte- and CD34-derived dendritic cells but not in monocytes and macrophages," Blood, vol. 98, no. 1, pp. 174-180, 2001.

[44] A. M. Woltman, S. W. Van der Kooij, P. J. Coffer, R. Offringa, M. R. Daha, and C. Van Kooten, "Rapamycin specifically interferes with GM-CSF signaling in human dendritic cells, leading to apoptosis via increased p27 expression," Blood, vol. 101, no. 4, pp. 1439-1445, 2003.

[45] P. Klangsinsirikul, G. I. Carter, J. L. Byrne, G. Hale, and N. H. Russell, "Campath-1G causes rapid depletion of circulating host dendritic cells (DCs) before allogeneic transplantation but does not delay donor DC reconstitution," Blood, vol. 99, no. 7, pp. 2586-2591, 2002.

[46] K. Sato, N. Yamashita, N. Yamashita, M. Baba, and T. Matsuyama, "Regulatory dendritic cells protect mice from murine acute graft-versus-host disease and leukemia relapse," Immunity, vol. 18, no. 3, pp. 367-379, 2003.

[47] S. Fujita, Y. Sato, K. Sato et al., "Regulatory dendritic cells protect against cutaneous chronic graft-versus-host disease mediated through CD4+CD25+Foxp3+ regulatory T cells," Blood, vol. 110, no. 10, pp. 3793-3803, 2007.

[48] K. Sato, K. Eizumi, T. Fukaya et al., "Naturally occurring regulatory dendritic cells regulate murine cutaneous chronic graft-versus-host disease," Blood, vol. 113, no. 19, pp. 47804789, 2009.

[49] Y. Huang, L. D. Bozulic, T. Miller, H. Xu, L.-R. Hussain, and S. T. Ildstad, "CD $8 \alpha+$ plasmacytoid precursor DCs induce antigen-specific regulatory $\mathrm{T}$ cells that enhance HSC engraftment in vivo," Blood, vol. 117, no. 8, pp. 2494-2505, 2011.

[50] I. J. Fugier-Vivier, F. Rezzoug, Y. Huang et al., "Plasmacytoid precursor dendritic cells facilitate allogeneic hematopoietic stem cell engraftment," Journal of Experimental Medicine, vol. 201, no. 3, pp. 373-383, 2005.

[51] A. Encabo, P. Solves, F. Carbonell-Uberos, and M. D. Miñana, "The functional immaturity of dendritic cells can be relevant to increased tolerance associated with cord blood transplantation," Transfusion, vol. 47, no. 2, pp. 272-279, 2007.

[52] J. A. Holloway, C. A. Thornton, N. D. Diaper, D. T. Howe, and J. O. Warner, "Phenotypic analysis of circulating dendritic cells during the second half of human gestation," Pediatric Allergy and Immunology, vol. 20, no. 2, pp. 119-125, 2009.

[53] M. Nguyen, E. Leuridan, T. Zhang et al., "Acquisition of adultlike TLR4 and TLR9 responses during the first year of life," PLoS ONE, vol. 5, no. 4, Article ID e10407, 2010.

[54] E. M. Clark, D. S. Joshi, A. B. Grimm, A. D. Joshi, P. Wang, and S. S. Joshi, "Ultrastructural basis of enhanced antitumor cytotoxicity of cord blood-derived CTLs: a comparative analysis with peripheral blood and bone marrow," International Journal of Oncology, vol. 37, no. 3, pp. 645-653, 2010.

[55] B. Adkins, C. Leclerc, and S. Marshall-Clarke, "Neonatal adaptive immunity comes of age," Nature Reviews Immunology, vol. 4, no. 7, pp. 553-564, 2004.

[56] C. B. Wilson, "Immunologic basis for increased susceptibility of the neonate to infection," Journal of Pediatrics, vol. 108, no. 1, pp. 1-12, 1986.

[57] M. Makhseed, R. Raghupathy, F. Azizieh, A. Omu, E. AlShamali, and L. Ashkanani, "Th1 and Th2 cytokine profiles in recurrent aborters with successful pregnancy and with subsequent abortions," Human Reproduction, vol. 16, no. 10, pp. 2219-2226, 2001.

[58] A. H. Liu and D. Y. M. Leung, "Renaissance of the hygiene hypothesis," Journal of Allergy and Clinical Immunology, vol. 117, no. 5, pp. 1063-1066, 2006.

[59] E. Gluckman, H. E. Broxmeyer, A. D. Auerbach et al., "Hematopoietic reconstitution in a patient with Fanconi's anemia by means of umbilical-cord blood from an HLAidentical sibling," New England Journal of Medicine, vol. 321, no. 17, pp. 1174-1178, 1989.

[60] J. A. Madrigal, S. B. A. Cohen, E. Gluckman, and D. J. Charron, "Does cord blood transplantation result in lower graft-versus-host disease? It takes more than two to tango," Human Immunology, vol. 56, no. 1-2, pp. 1-5, 1997.

[61] P. Han, G. Hodge, C. Story, and X. Xu, "Phenotypic analysis of functional T-lymphocyte subtypes and natural killer cells in human cord blood: relevance to umbilical cord blood transplantation," British Journal of Haematology, vol. 89, no. 4, pp. 733-740, 1995.

[62] M. G. Roncarolo, M. Bigler, E. Ciuti, S. Martino, and P. A. Tovo, "Immune responses by cord blood cells," Blood Cells, vol. 20, no. 2-3, pp. 573-586, 1994.

[63] G. Risdon, J. Gaddy, and H. E. Broxmeyer, "Allogeneic responses of human umbilical cord blood," Blood Cells, vol. 20, no. 2-3, pp. 566-572, 1994.

[64] J. H. F. Falkenburg, S. A. P. Van Luxemburg-Heijs, F. T. H. Lim, H. H. H. Kanhai, and R. Willemze, "Umbilical cord blood contains normal frequencies of cytotoxic T-lymphocyte precursors (ctlp) and helper T-lymphocyte precursors against noninherited maternal antigens and noninherited paternal antigens," Annals of Hematology, vol. 72, no. 4, pp. 260-264, 1996.

[65] S. B. A. Cohen, I. Perez-Cruz, P. Fallen, E. Gluckman, and J. A. Madrigal, "Analysis of the cytokine production by cord and 
adult blood," Human Immunology, vol. 60, no. 4, pp. 331-336, 1999.

[66] A. Román, M. Rodríguez, M. A. Herraiz et al., "Heterogeneous expression of HLA-G1, -G2, -G5, -G6, and -G7 in myeloid and plasmacytoid dendritic cells isolated from umbilical cord blood," Human Immunology, vol. 70, no. 2, pp. 104-109, 2009.

[67] D. W. C. Hunt, H. I. Huppertz, H. J. Jiang, and R. E. Petty, "Studies of human cord blood dendritic cells: evidence for functional immaturity," Blood, vol. 84, no. 12, pp. 4333-4343, 1994.

[68] I. Crespo, A. Paiva, A. Couceiro, P. Pimentel, A. Orfão, and F. Regateiro, "Immunophenotypic and functional characterization of cord blood dendritic cells," Stem Cells and Development, vol. 13, no. 1, pp. 63-70, 2004.

[69] J. Almeida, C. Bueno, M. C. Alguero et al., "Extensive characterization of the immunophenotype and pattern of cytokine production by distinct subpopulations of normal human peripheral blood MHC II+/lineage-cells," Clinical and Experimental Immunology, vol. 118, no. 3, pp. 392-401, 1999.

[70] C. Bueno, J. Almeida, M. C. Alguero et al., "Flow cytometric analysis of cytokine production by normal human peripheral blood dendritic cells and monocytes: comparative analysis of different stimuli, secretion-blocking agents and incubation periods," Communications in Clinical Cytometry, vol. 46, no. 1, pp. 33-40, 2001.

[71] A. Moretta, R. Maccario, F. Fagioli et al., "Analysis of immune reconstitution in children undergoing cord blood transplantation," Experimental Hematology, vol. 29, no. 3, pp. 371-379, 2001.

[72] F. M. Marty, J. Bryar, S. K. Browne et al., "Sirolimusbased graft-versus-host disease prophylaxis protects against cytomegalovirus reactivation after allogeneic hematopoietic stem cell transplantation: a cohort analysis," Blood, vol. 110, no. 2, pp. 490-500, 2007.

[73] K. Beck, U. Meyer-König, M. Weidmann, C. Nern, and F. T. Hufert, "Human cytomegalovirus impairs dendritic cell function: a novel mechanism of human cytomegalovirus immune escape," European Journal of Immunology, vol. 33, no. 6, pp. 1528-1538, 2003.

[74] M. Arpinati, G. Chirumbolo, B. Urbini et al., "Acute graftversus-host disease and steroid treatment impair CD11c+ and CD123+ dendritic cell reconstitution after allogeneic peripheral blood stem cell transplantation," Biology of Blood and Marrow Transplantation, vol. 10, no. 2, pp. 106-115, 2004.

[75] S. Yamasaki, Y. Heike, S. Mori et al., "Infectious complications in chronic graft-versus-host disease: a retrospective study of 145 recipients of allogeneic hematopoietic stem cell transplantation with reduced- and conventional-intensity conditioning regimens," Transplant Infectious Disease, vol. 10, no. 4, pp. 252-259, 2008.

[76] X. C. Wei, X. H. Zhai, X. R. Han, D. D. Yang, and Q. S. Wang, "Influence of dendritic cells on biological activity of the homologous CIK cells and its anti-leukemia effect in vitro," Zhongguo Shi Yan Xue Ye Xue Za Zhi, vol. 18, pp. 946-951, 2010. 

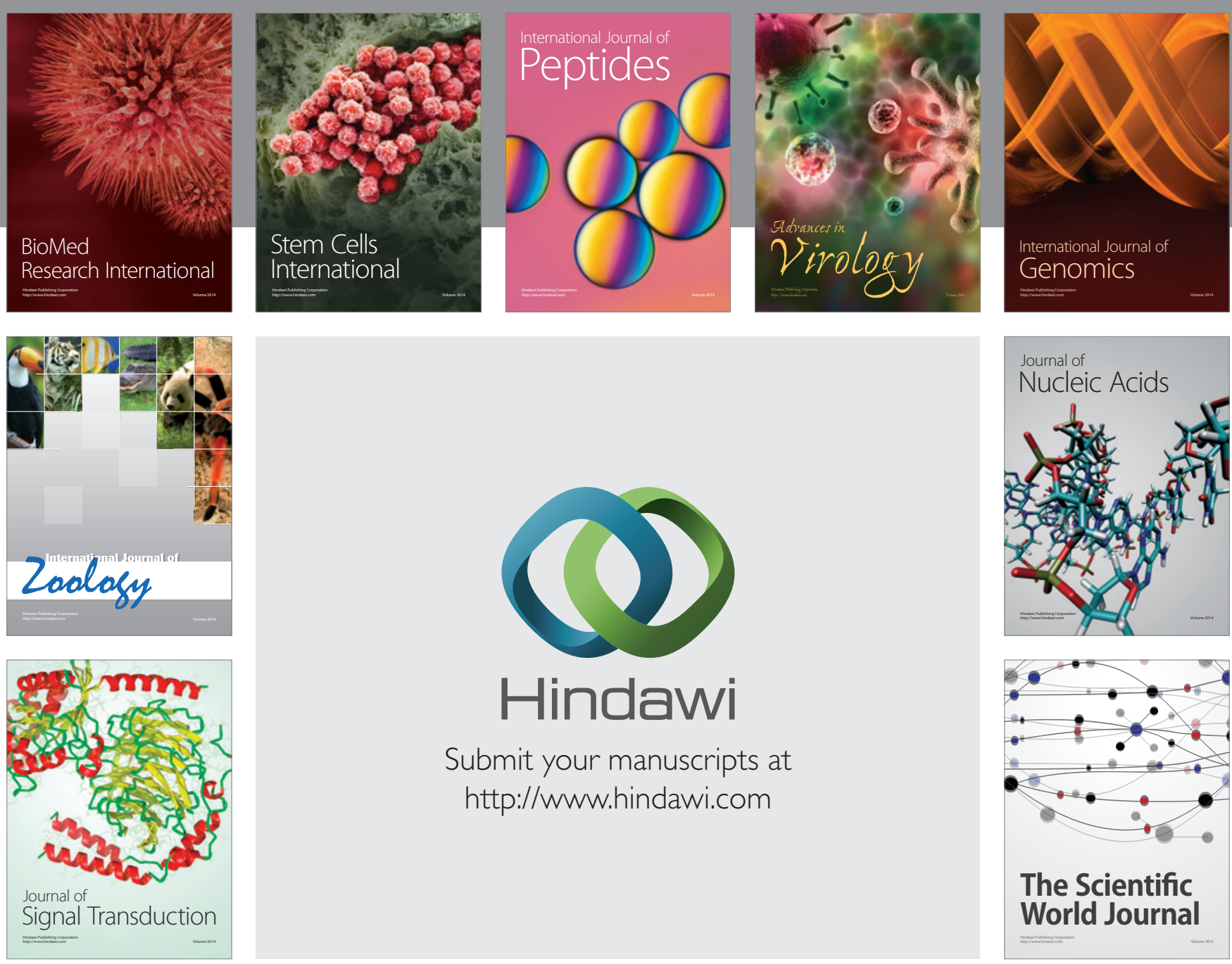

Submit your manuscripts at

http://www.hindawi.com
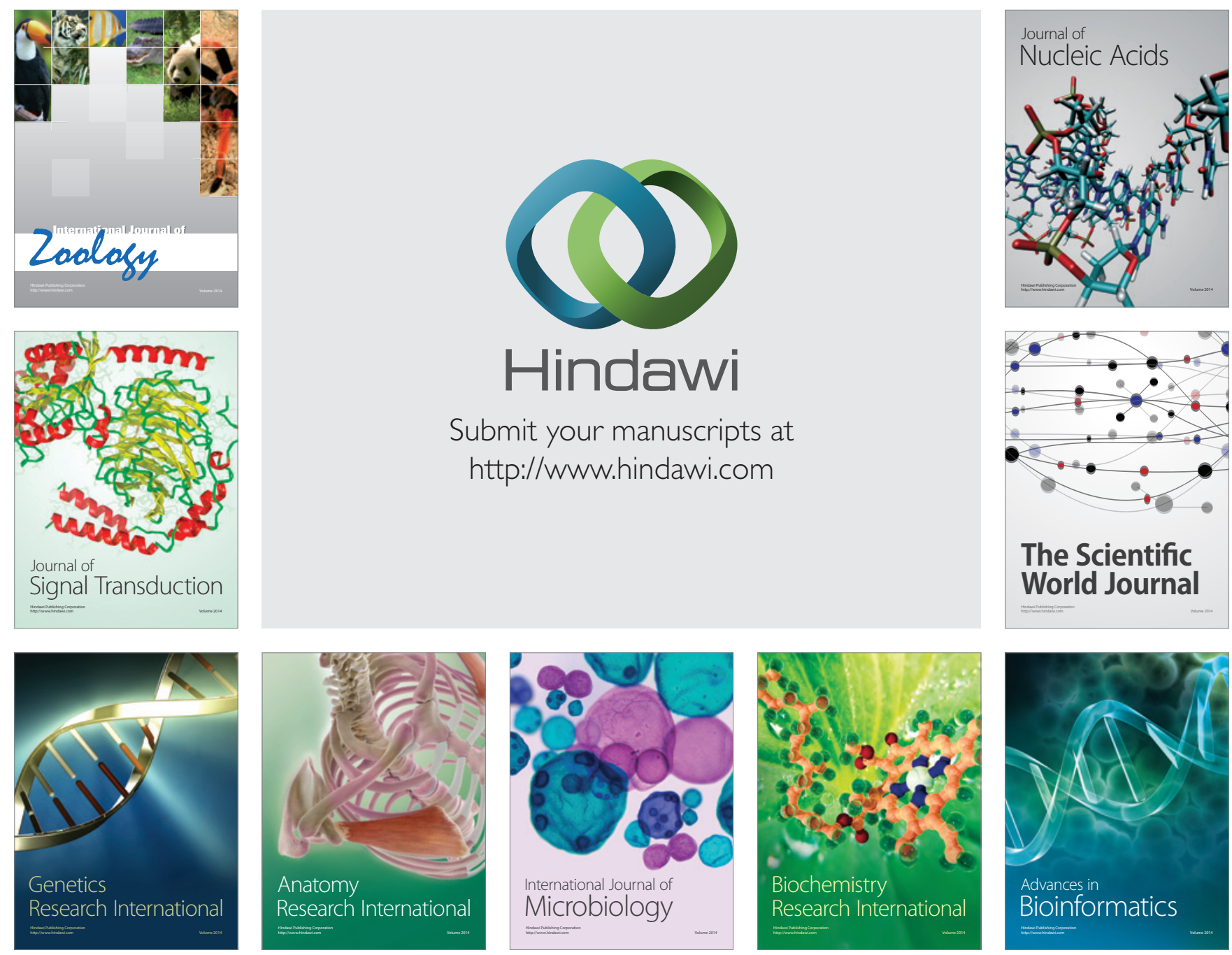

The Scientific World Journal
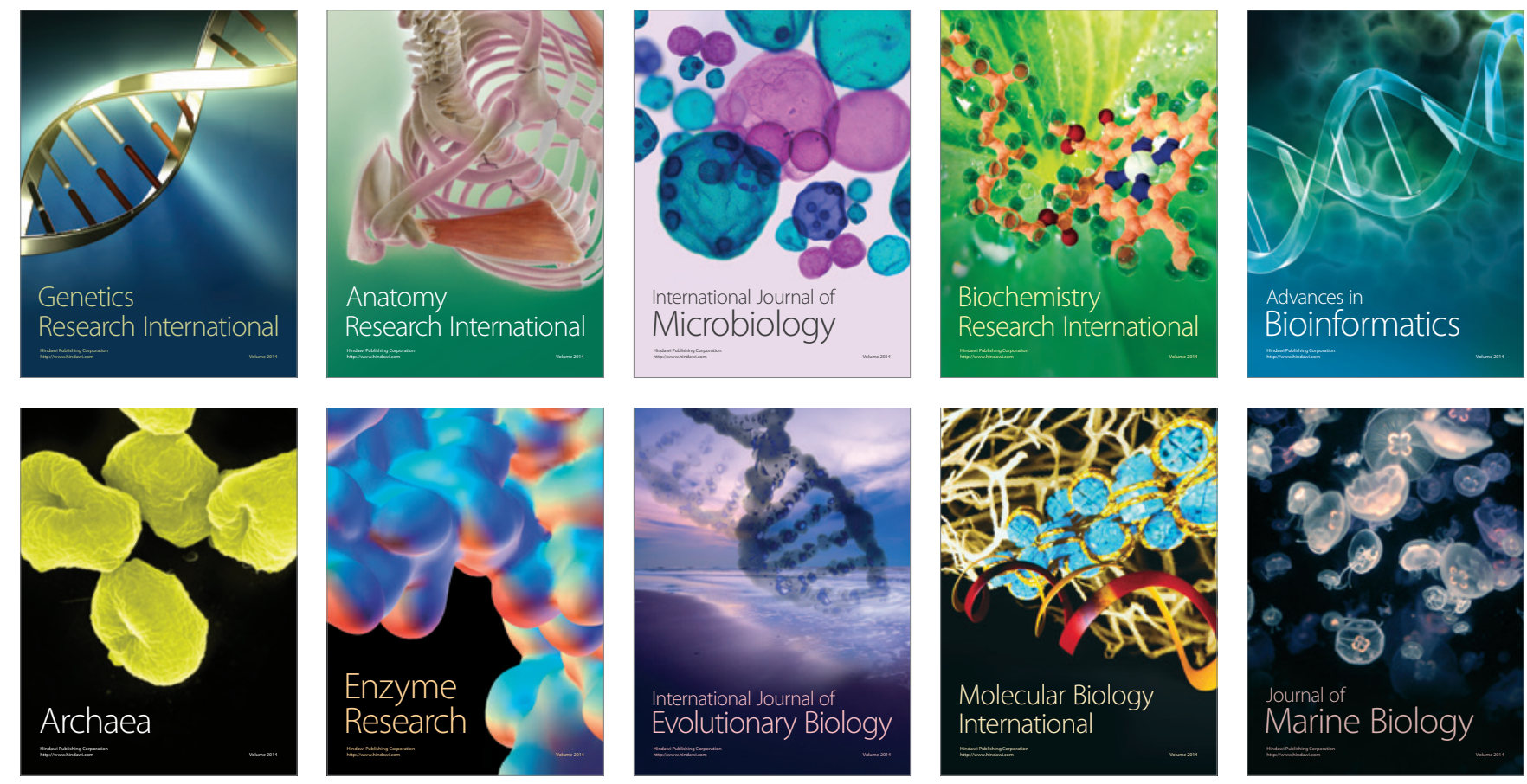